\title{
No Influence of Age-Related Hearing Loss on Brain Amyloid- $\beta$
}

\author{
Julia Z. Sarant ${ }^{\mathrm{a}, *}$, David C. Harris ${ }^{\mathrm{a}}$, Peter A. Busby ${ }^{\mathrm{a}}$, Christopher Fowler ${ }^{\mathrm{b}}$, Jurgen Fripp ${ }^{\mathrm{c}}$, \\ Colin L. Masters ${ }^{\mathrm{b}}$ and Paul Maruff ${ }^{\mathrm{d}}$ \\ ${ }^{\mathrm{a}}$ The University of Melbourne, Melbourne, Australia \\ ${ }^{\mathrm{b}}$ The Florey Institute, Melbourne, Australia \\ ${ }^{\mathrm{c} C o m m o n w e a l t h ~ S c i e n t i f i c ~ a n d ~ I n d u s t r i a l ~ R e s e a r c h ~ O r g a n i z a t i o n, ~ Q u e e n s l a n d, ~ A u s t r a l i a ~}$ \\ ${ }^{\mathrm{d}}$ Cogstate, Melbourne, Australia
}

Handling Associate Editor: Barbara Bendlin

Accepted 13 October 2021

Pre-press 18 November 2021

\begin{abstract}
.
Background: Hearing loss is independently associated with a faster rate of cognitive decline in older adults and has been identified as a modifiable risk factor for dementia. The mechanism for this association is unknown, and there has been limited exploration of potential casual pathology.

Objective: Our objective was to investigate whether there was an association between degree of audiometrically measured hearing loss $(\mathrm{HL})$ and brain amyloid- $\beta(\mathrm{A} \beta)$ in a pre-clinical sample.

Methods: Participants of the Australian Imaging and Biomarker Longitudinal Study (AIBL; $n=143$ ) underwent positron emission tomography (PET) imaging and objective measurement of hearing thresholds within 5 years of imaging, as well as cognitive assessment within 2 years of imaging in this observational cohort study.

Results: With one exception, study participants who had cognitive assessments within 2 years of their PET imaging $(n=113)$ were classified as having normal cognition. There was no association between cognitive scores and degree of hearing loss, or between cognitive scores and $A \beta$ load. No association between HL and A $\beta$ load was found once age was controlled for. As previously reported, positive Apolipoprotein E4 (APOE4) carrier status increased the risk of being A $\beta$ positive $(p=0.002)$.

Conclusion: Degree of HL was not associated with positive $A \beta$ status.
\end{abstract}

Keywords: Amyloid, cognition, dementia, hearing loss, neuroimaging

\section{INTRODUCTION}

Hearing loss (HL) occurs in up to $80 \%$ of adults aged over 65 years $[1,2]$. A pure tone average (PTA) of greater than $20 \mathrm{~dB}$ hearing level is defined as hearing loss in accordance with World Health Organization criteria [3]. Epidemiological data shows HL to be associated independently with cognitive decline

\footnotetext{
*Correspondence to: Julia Sarant, PhD, Department of Audiology and Speech Pathology, The University of Melbourne, 550 Swanston Street, Carlton, Victoria 3010, Australia. Tel.: +61 03 9035 5325; E-mail: jsarant@unimelb.edu.au.
}

and dementia in older adults $[4,5]$, with the risk of cognitive decline increasing with increased HL such that compared to an individual with no HL, older adults with mild HL have twice the risk of incident dementia, and those with severe HL have a five-fold risk [6]. Recent population-based cohort studies also report that individuals with onset of HL in middle age (45-64 years) have the highest dementia risk compared with older adults with normal hearing (adjusted hazard ratios of 1.90 and 1.70 , respectively $[7,8]$ ). In many older adults, HL can be ameliorated with hearing aid or cochlear implant use, showing this risk factor for dementia to be potentially modifiable 
[6]. Despite the strong evidence for their association, the processes that link HL to faster cognitive decline in older adults remain unknown. One primary hypothesis is that HL may arise from the same early neurodegenerative processes that give rise to dementia. However, there is limited research examining relationships between HL and biomarkers associated with dementia in preclinical populations.

Alzheimer's disease (AD) is the most common form of dementia, with estimates suggesting it accounts for 60-80\% of cases [9]. Advances in understanding AD biology have allowed the application of amyloid biomarkers to identify the disease in the preclinical stages and confirm its presence in symptomatic individuals. While adults with preclinical $\mathrm{AD}$ do not have cognitive impairment, they do show subtle but relentless cognitive decline, faster atrophy of cortical brain areas, and an increased rate of progression to clinically recognizable mild cognitive impairment or dementia $[10,11]$. Therefore, studying HL in preclinical AD provides an opportunity to understand the nature and magnitude of relationships between $\mathrm{AD}$-specific neurodegeneration and HL in the absence of cognitive impairment. If AD-related neurodegeneration is related to HL, then indices of $\mathrm{HL}$ will be greater in preclinical AD than in age-matched controls. The current study aimed to examine the association between degree of HL and amyloid- $\beta$ (A $\beta$ ) using objective audiological measurement of HL.

\section{MATERIALS AND METHODS}

\section{Participants}

Participants in this study were older adults (aged 50 years and over) enrolled in the Australian Imaging Biomarkers and Lifestyle (AIBL) Study, a prospective longitudinal cohort study of aging and AD [12]. Individuals from this cohort who did not have a mild cognitive impairment or dementia diagnosis underwent positron emission tomography (PET) imaging, had an objective audiometric assessment of their hearing within 5 years of their scans, had cognitive assessment within 2 years of their PET scan, and had no diagnosed mild cognitive impairment or dementia were selected $(n=143)$.

\section{Objective assessment of hearing}

Pure tone audiometry was used to measure air and bone conduction thresholds at 500, 1000, 2000, and $4000 \mathrm{~Hz}$ bilaterally. Bone conduction testing was conducted when an interaural difference of $>10 \mathrm{dBHL}$ in air conduction thresholds was identified. Testing was conducted by an audiologist using portable equipment in participants' homes. Background noise levels, measured using a sound level meter, were no greater than $40 \mathrm{dBSPL}$, as per recommended practice. Participants' ears were also examined for wax occlusion and collapsed ear canals. PTAs (average of hearing thresholds at 500, 1000, 2000 , and $4000 \mathrm{~Hz}$ ) were calculated. A PTA of greater than or equal to $20 \mathrm{dBHL}$ was defined as HL, according to the World Health Organization criteria [3]. Participant self-reported hearing aid use was also noted (yes/no) and $A P O E$ genotyping was undertaken.

\section{PET imaging methods and analysis}

$A \beta$ PET imaging was conducted using the $A \beta$ tracers: ${ }^{11} \mathrm{C}$-PiB, ${ }^{18} \mathrm{~F}$-florbetapir, or ${ }^{18} \mathrm{~F}$-flutemetamol. PET acquisitions were performed $40-70$ min posttracer injection (PI) for ${ }^{11} \mathrm{C}-\mathrm{PiB}, 50-70 \mathrm{~min} \mathrm{PI}$ for ${ }^{18} \mathrm{~F}$-florbetapir, and $90-110 \mathrm{~min}$ PI for ${ }^{18} \mathrm{~F}$ flutemetamol. PET images were not corrected for partial volume. All A $\beta$ PET scans were quantified using CapAIBL [13] and the $A \beta$ level was expressed in Centiloids (CL) as described previously $[14,15]$. $\mathrm{A} \beta$ level was classified according to five categories: < 15 Negative, 15-25 CL uncertain, 26-50 CL moderate, 51-100 CL high, $100 \mathrm{CL}$ very high. 3T MRI three-dimensional magnetizationprepared rapid gradient-echo (3DMPRAGE) was used to measure hippocampal volume (HV) corrected for intracranial brain volume. A sagittal 3D FLAIR image was used to quantify white matter lesion size based on spatial location (total, lobar, and deep) [16].

\section{Cognitive assessment}

Cognition was assessed by psychologists using the Cogstate Cognitive Battery [17-20] which comprises assessments of psychomotor function, attention, working memory, and visual learning. The Cogstate Battery is a computerized test battery developed for repeated assessment of cognitive performance. The battery is highly reliable (test-retest reliability for each measure ranges between 0.84-0.94), facilitates minimal practice effects [17], and is relatively quick to administer (approximately $30 \mathrm{~min}$, depending on ability). The Cogstate Battery can detect decline in cognitive function that does not affect function in 
everyday life over even a 6-month period [21]. The battery is visually presented and is therefore suitable for people with HL. Speed and accuracy of responses are recorded and transformed on a centralized platform to give normalized data distributions [17, 18]. A composite working memory/visual learning score was derived to classify participants as cognitively normal or abnormal. In older adults, Cogstate measures of information processing speed, attention, and memory are highly sensitive to cognitive dysfunction and longitudinal cognitive decline [22, 23].

\section{Statistical analysis}

Participant characteristics were described using means, SDs, and minima and maxima for continuous variables, and counts, percentages, and cross tabulations for categorical variables. Pearson's correlations were used to examine the associations between HL and cognitive function and between $A \beta$ load and cognitive function. Linear regression analysis was used to investigate the relationship of $\mathrm{A} \beta$ load with HL, age, and $A P O E \varepsilon 4$ status. Two sensitivity analyses of the regression results for the continuous measurement of $A \beta$ load were carried out—one categorizing $A \beta$ load as normal (less than 15) or abnormal (above 15) and fitting a Probit model with HL, age, and $A P O E \varepsilon 4$ status, and a second with $A \beta$ load in ordered categories negative/uncertain/moderate/high/very high as above and fitting an Ordered Probit model with HL, age, and $A P O E \& 4$ status. Further regression models for $\mathrm{A} \beta$ using hearing loss by individual hearing frequencies separately $(500,1000,2000$, and $4000 \mathrm{~Hz})$ were also conducted as a sensitivity analysis. A reported sex effect in the relationship between hearing loss and cognition [24] motivated an additional sensitivity analysis. Controlling for sex in each of the statistical models (Table 2) did not alter the results.

\section{Data availability}

All data has been published within this article. Data from AIBL are available to the public on request. Requests for audiometric data will be considered by the authors.

\section{Standard protocol approvals, registrations, and patient consents}

This study was carried out in accordance with the recommendations of the Australian National Health and Medical Research Council guidelines
Table 1

Demographic, clinical, and pathological characteristics by HL status

\begin{tabular}{lcccc}
\hline & All & $\begin{array}{c}\text { Normal } \\
\text { hearing }\end{array}$ & $\begin{array}{c}\text { Hearing } \\
\text { loss }\end{array}$ & $p$ \\
\hline$n$ & 143 & 72 & 71 & \\
Age (y) & 75.1 & 73.2 & 77.1 & 0.000 \\
Pure Tone Average (dB) & 26.9 & 17.1 & 36.8 & 0.000 \\
Hearing aid use (\%) & 27.0 & 7.0 & 47.1 & 0.000 \\
Female $(\%)$ & 58.3 & 63.4 & 59.3 & 0.215 \\
APOE4 $(\%)$ & 24.1 & 26.8 & 21.4 & 0.463 \\
A $\beta$ positive $(\%)$ & 23.8 & 18.1 & 29.6 & 0.108 \\
\hline
\end{tabular}

for ethical research conduct. The study protocol was approved by the University of Melbourne Behavioural and Social Sciences Human Ethics SubCommittee (Ethics ID: 1646925). All participants gave written informed consent in accordance with the Declaration of Helsinki.

\section{RESULTS}

\section{Clinical and pathologic characteristics of the cohort}

Cohort characteristics are detailed in Table 1 according to hearing status. Participant ages ranged from 65.5 to 96.6 years. Approximately two thirds of the sample had HL (67.1\%), which was on average mild in magnitude (calculated based on average PTAs re ANSI-1969 for 500, 1000, 2000, and $4000 \mathrm{~Hz}$ ) [25], consistent with prevalence statistics for older adults in this age range. Only $27 \%$ used hearing aids. A significantly greater number of males had HL $(75.9 \% ; p=0.037)$, with $59.3 \%$ of females with HL. There was no difference in prevalence of APOE4 or cardiovascular conditions between males and females. Forty-six percent of participants had more than 15 years of education. Only one of the 113 participants with cognitive assessment data within 2 years of their PET scan had cognitive impairment. Given this, there was no difference in composite working memory/visual learning score between the groups with $\mathrm{HL}$ and normal hearing. There was also no association between cognitive scores and degree of hearing loss, or between cognitive scores and $A \beta$ load. Both HL and $\mathrm{A} \beta$ pathology increased with age ( $r=0.50, p=0.000 ; r=0.31, p=0.000$ respectively), as shown in Figs. 1 and 2. There was no significant difference in $A \beta$ pathology between participants with and without HL (26\% with HL were $A \beta$ positive, versus $19.1 \%$ without HL, $p>0.05$ ). This result indicates that HL could be due to age in participants who 


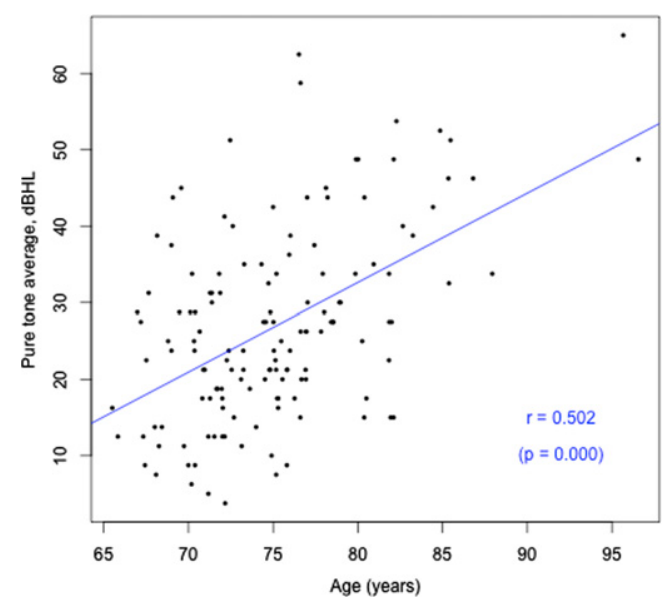

Fig. 1. Age (years) versus HL (better ear PTA, dBHL).

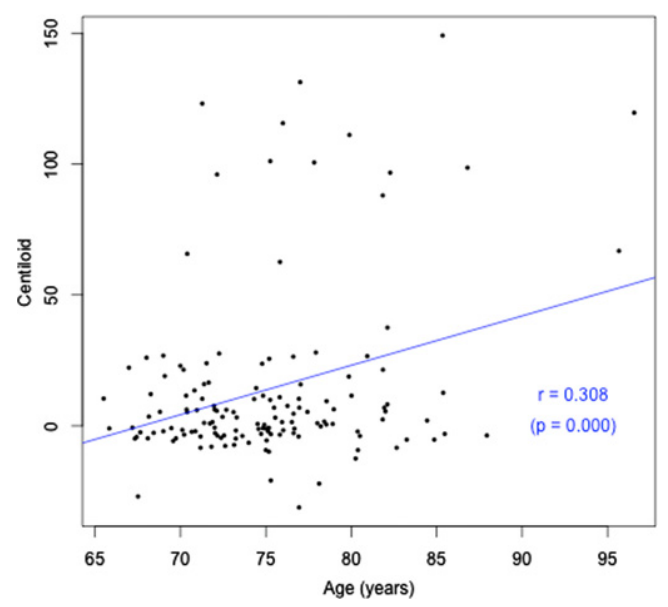

Fig. 2. Age (years) versus $A \beta$ load (CL).

had HL but were A $\beta$ negative but does not allow for explanation of the cause of HL for those who were $\mathrm{A} \beta$ positive.

\section{Relationship between $H L$ and $A \beta$ levels}

Amyloid levels were not different between samples classified according to the presence or absence of $\mathrm{HL}$ (Table 1). Similarly, indices of HL were not different between samples classified according to whether amyloid levels were normal or abnormal (Table 2). However, with amyloid level and HL defined as continuous measures a significant positive relationship between the two was observed $(r=0.23 . p=0.005$; Fig. 3). However, this association was not evident when the common effect of age was entered into the model. Sensitivity analyses of hearing loss by hearing
Table 2

Statistical models for $\mathrm{A} \beta$ using pure tone average

\begin{tabular}{lccc}
\hline & $\begin{array}{c}\text { Model A: } \\
\text { Regression }\end{array}$ & $\begin{array}{c}\text { Model B: } \\
\text { Probit }\end{array}$ & $\begin{array}{r}\text { Model C: } \\
\text { Ordered }\end{array}$ \\
\hline Intercept & -115.28 & -3.04 & \\
& $(0.005)$ & $(0.103)$ & \\
PTA (dB) & 0.24 & 0.01 & 0.01 \\
& $(0.376)$ & $(0.553)$ & $(0.519)$ \\
Age (y) & 1.52 & 0.02 & 0.04 \\
& $(0.008)$ & $(0.383)$ & $(0.141)$ \\
APOE4 & 25.23 & 1.02 & 1.01 \\
& $(0.000)$ & $(0.000)$ & $(0.000)$ \\
HA use & 8.45 & 0.47 & 0.41 \\
& $(0.255)$ & $(0.169)$ & $(0.208)$ \\
n & 137 & 137 & \\
R-squared & 0.218 & & \\
\hline
\end{tabular}

For all models, statistical model coefficients are reported, with $p$ values in brackets. In model $\mathrm{A}, \mathrm{A} \beta$ is treated as a continuous measure. For model $\mathrm{B}, \mathrm{A} \beta$ is classified according to positive or negative status. In model $\mathrm{C}, \mathrm{A} \beta$ status is classified according to the 5 categories of Centiloid status.

Table 3

Statistical models for $A \beta$ using hearing loss by hearing frequency

\begin{tabular}{lccc}
\hline & $\begin{array}{c}\text { Model A: } \\
\text { Regression }\end{array}$ & $\begin{array}{c}\text { Model B: } \\
\text { Probit }\end{array}$ & $\begin{array}{c}\text { Model C: } \\
\text { Ordered }\end{array}$ \\
\hline Intercept & -82.50 & -2.21 & NA \\
& $(0.055)$ & $(0.270)$ & (NA) \\
$500 \mathrm{~Hz}$ & 0.04 & 0.02 & 0.02 \\
& $(0.920)$ & $(0.381)$ & $(0.391)$ \\
$1000 \mathrm{~Hz}$ & -0.11 & -0.03 & -0.02 \\
& $(0.813)$ & $(0.418)$ & $(0.275)$ \\
$2000 \mathrm{~Hz}$ & 0.02 & 0.01 & 0.01 \\
& $(0.951)$ & $(0.546)$ & $(0.692)$ \\
$4000 \mathrm{~Hz}$ & 0.22 & 0.01 & 0.01 \\
& $(0.283)$ & $(0.360)$ & $(0.355)$ \\
Age (y) & 1.06 & 0.01 & 0.02 \\
& $(0.080)$ & $(0.725)$ & $(0.451)$ \\
APOE & 26.40 & 1.03 & 1.03 \\
& $(0.000)$ & $(0.000)$ & $(0.000)$ \\
HA use & 9.47 & 0.56 & 0.47 \\
& $(0.212)$ & $(0.114)$ & $(0.163)$ \\
R-squared & 0.207 & & \\
\hline
\end{tabular}

frequency yielded the same result (Table 3). Analyses examining the association between amyloid level and HL with age controlled are summarized in Table 2. Model A, a linear regression for the continuous measure of $A \beta$ load in $C L$, found HL was not a significant predictor for $\mathrm{A} \beta$ load after controlling for age and APOE4 status. This same outcome was observed in sensitivity analyses that classified amyloid level in terms of a binary classification (i.e., normal versus abnormal; Table 3, Model B), or according to the five ordinal categories $(14,15)$; Table 3, Model C). 


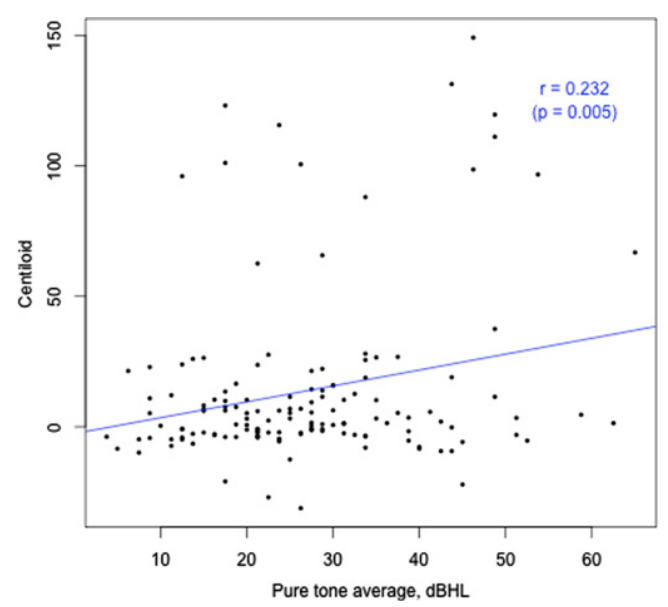

Fig. 3. Hearing loss (PTA, better ear, dBHL) versus A $\beta$ load (CL).

\section{DISCUSSION}

In this cross-sectional cohort of participants with and without HL who underwent PET examination, HL was not associated with brain $A \beta$ once the age of individuals was controlled, irrespective of whether amyloid level was considered as a continuous, binary, or five-level ordinal measure. Without age controlled in the analyses, a weak association between amyloid level and HL was observed. While neither amyloid level or HL were used as inclusion criteria for this study, the number of participants with abnormally high amyloid did not differ significantly between those with and without HL. We observed in these cognitively normal older adults that both HL and amyloid level increased with increasing age. These relationships have been described previously in many studies (e.g., [2, 26-28]), therefore should be controlled in investigations of the relationship between brain $A \beta$ and HL. The fact that both A $\beta$ deposition and HL are correlated with age confounded the current analysis, as there was likely collinearity between them. Despite the distribution of severity of HL in this sample being representative of the general population of older adults, as the average severity of HL in this sample was only mild, statistical power to detect any effect of HL on brain $\mathrm{A} \beta$ may have been limited. Only $27 \%$ of participants with HL used HAs, which may have limited power to detect any effect of HA use in this sample. Strengths of this study are that it is the largest sample to date of preclinical older adults with HL ( $n=142$; [29-32]), objective audiometric assessment of HL, objective non-screening cognitive assessment data obtained through visual, not auditory, presentation, and the use of the Centiloid scale to allow comparison across different tracers and sites.

The data from this study and three of four others examining the relation between HL and $A \beta$ suggest that indices of $A \beta$ are not increased in older adults with HL. Three initial studies (two imaging, one via autopsy) investigated whether there was an association between HL and $A \beta$, with all reporting no association [30-32]. However, all three studies were subject to significant methodological limitations. Primary limitations include small numbers of preclinical participants with HL (e.g., $n=27,28$; number unknown for the third study, but 55 hearing aid users of unknown cognitive status), unreliable HL data for two of the studies (HL was defined according to the opinions of others who had interacted with participants in one study, and the method of HL diagnosis was unknown in another, even to the investigators), unrepresentative HL prevalence in samples, and the use of auditorily presented screening cognitive assessments to participants with HL, which may have confounded cognitive results. Given these limitations, the results of these studies do not provide a firm basis for the development of brain behavior models of HL in dementia [33].

Only one further study has examined the association between $\mathrm{HL}$ and $\mathrm{A} \beta$, and in contrast reported a weak baseline association between HL and brain $\mathrm{A} \beta$ (equivalent to an increase of approx. 3 CLs for participants with HL) [29], in a younger sample (64 \pm 3.5 years). The reported relationship between global amyloid SUVR (using a different radioisotope) and suprathreshold speech perception results appears likely to be driven by two poorly performing outliers, with only $15 / 98$ participants not showing a ceiling effect on the speech perception task. However, the PTA data also demonstrated this relationship, despite the small number of participants with HL and average mild HL ( $n=23$; PTA $=33 \mathrm{dBHL})$. The cohort had a narrow age range ( $\mathrm{SD} \pm 3.5$ years), therefore the usual association between HL and age observed in the current study was not seen. While this study used objective measurement of HL, the generalizability of the results is again limited by small sample size (only 23 participants had HL, and only 2 used hearing aids) and a lack of cognitive data to determine whether participants were cognitively healthy.

Models of pre-clinical disease show that the accumulation of the amyloid protein in the brain is an early initiating event in the $\mathrm{AD}$ cascade [27, 34]. Although predicted by positive $A \beta$ pathology, the 
onset of dementia can take decades to develop [27, 35 ], giving a window of time for potential modification of the cognitive outcome. Mixed [36], small [37], and sometimes no association [38] between $\mathrm{A} \beta$ pathology and cognitive impairment have been reported, with $A \beta$ plaques commonly observed in the brains of clinically normal individuals, indicating that $\mathrm{A} \beta$ pathology is not the only driver of dementia. The sequence of events in the AD cascade, as well as the mechanisms by which $A \beta$ pathology impacts on neuronal integrity and subsequent clinical dementia symptoms, are still unknown despite decades of research.

Previous volumetric MRI studies of brain structure as a measure of neurodegeneration have reported changes in brain structure associated with HL. Human and animal neuroimaging studies of individuals with hearing loss have shown reduced auditory cortex volume [39], white matter tract dysfunction and decline [40, 41], and accelerated whole brain atrophy [42] in degenerative patterns similar to those of $\mathrm{AD}$ patients. However, despite many reports of the independent association between HL and dementia, the mechanisms for this association also remain unknown. These are likely to be multiple, and there are several hypotheses. The common cause hypothesis postulates degeneration of both cognitive and non-cognitive processes due to a common neuropathic origin, while the cascade hypothesis proposes that sensory degradation causes a reduction in auditory signaling, leading to the atrophy of brain structures. The cognitive load theory hypothesizes that increased cognitive load due to perceptual difficulties that occur with HL causes diversion of cognitive resources towards speech processing rather than working memory tasks. A fourth theory proposes that dementia is caused by psychological sequalae of HL such as social isolation, depression, and loneliness, which are known risk factors for dementia [43]. A recent study has postulated a genetic relationship between $\mathrm{HL}$ and $\mathrm{AD}$, supporting mounting evidence for the importance of inflammatory pathways in $\mathrm{AD}$ and suggesting that the relationship between hearing loss and AD may be due, in part, to shared genes and immune response pathways between both conditions [33]. A final recent theory postulates that changes in brain activity related to listening difficulties with HL cause irreversible molecular degenerative damage, increasing the protein pathologies associated with $\mathrm{AD}$ [44]. It is unlikely that dementia could cause cochlear dysfunction, as the number of adults with HL who do not have clinical pathology far exceeds the number with both pathologies, it is widely reported that peripheral HL generally precedes dementia [4-6, 45], and neuropathologic evidence of AD has not been found in the peripheral auditory pathway to date [46].

The current lack of evidence for an association between peripheral HL and AD pathology, however, does not exclude other potential explanations for the widely observed association between HL and dementia. Firstly, it is important to note that dementia is not equivalent to $\mathrm{AD}$, and that as most previous studies of HL and cognitive decline have not utilized biomarkers of $\mathrm{AD}$, it is possible that the observed association between HL and dementia is being driven by vascular and/or other comorbid pathologies. Further, $\mathrm{AD}$ pathology is not simply equivalent to brain amyloid, as is evident in the null association between $\mathrm{A} \beta$ load and cognitive function in the current study. There is mounting recent evidence that tau pathology may play a synergistic role in driving the clinical expression of $\mathrm{AD}[47,48]$. The timeframe for the development of clinical AD in participants of this study who are $A \beta$ positive is currently unknown, which also leaves open the possibility that HL may influence the spread of tau pathology (age-related $\mathrm{HL}$ is reported to be associated with elevated cerebrospinal fluid tau levels and atrophy of the entorhinal cortex [32]), and therefore the subsequent development of AD. This theory may be proven with longitudinal follow-up of the participants in this study and in others including measurement of brain tau deposition.

Finally, it is important to note that pure tone audiometry is only one form of measurement of hearing impairment and may not necessarily give the best estimate of real-life hearing function, given the use of pure tones, not speech, in a quiet listening environment in this assessment method. All major neurodegenerative pathologies are associated with auditory brain dysfunction and have clinically relevant phenotypes of central hearing impairment [51]. In particular, auditory scene processing deficits, apparent in poor performance on speech-in-noise tests, are a common prodromal marker of more generalized cognitive decline and increased risk of $\mathrm{AD}$ [49-50]. Auditory dysfunction is present in AD in terms of auditory scene analysis, in Lewy body disease in the form of auditory hallucinations, impaired auditory scene analysis, tone or rhythm processing, and in the frontotemporal dementias as deficits in rhythm, pitch and timbre perception [51]. As argued previously, it is therefore plausible that some of the 
observed association between HL and dementia may be reflective of central auditory processing dysfunction/decline [51]. Also as noted previously, a focus on audiometric measures of HL may underestimate the association between auditory dysfunction and cognitive decline, particularly since impaired auditory scene analysis may not be evident in assessments conducted in quiet listening environments and can be present in the absence of any elevation of puretone audiometric thresholds [52]. Given the lack of central auditory processing data in the current study (as with all cross-sectional biomarker studies conducted to date), we were unable to detect whether HL in participants was peripheral only, involved central auditory processing deficits in addition to elevated audiometric thresholds, or involved only the former in the absence of audiometric HL.

The question of how HL may be related to dementia currently remains unanswered. Given the limited state of knowledge of dementia causes and the relationship between HL and neuropathologic changes, including $A \beta$ deposition, further investigations are needed. Future studies of the association between HL and neurodegenerative biomarkers of $\mathrm{AD}$ (potentially including plasma neurofilament light) as a prognostic marker of both cognitive decline and changes measured via neuroimaging [53]) should include larger sample sizes (including greater numbers of participants with HL, a wider spread of HL, and hearing aid users), and neuroimaging follow-up coincident with longitudinal objective assessments of HL and cognition. Such studies would ideally follow individuals through to clinical dementia and should include the assessment of central auditory processing abilities.

\section{ACKNOWLEDGMENTS}

The authors wish to express their gratitude to the participants of this study. We thank audiologists Manasi Canagasabey, Jocelyn Phillips, Grace Nixon, and Patrick Bowers for their work on data collection. We thank Cogstate Ltd. for the provision of the Cogstate software and for ongoing support and advice regarding data interpretation from $\mathrm{Dr}$ Adrian Schembri. We are also grateful for support of the clinical audiology team of The University of Melbourne Academic Hearing Aids Clinic.

This study was supported by Australian Research Council Linkage grant LP150101180. The AIBL study has received partial financial support provided by the Alzheimer's Association (US), the
Alzheimer's Drug Discovery Foundation, an Anonymous foundation, the Science and Industry Endowment Fund, the Dementia Collaborative Research Centres, the Victorian Government's Operational Infrastructure Support Program, the McCusker Alzheimer's Research Foundation, the National Health and Medical Research Council, and the Yulgilbar Foundation. Numerous commercial interactions have supported data collection and analysis.

Authors' disclosures available online (https:// www.j-alz.com/manuscript-disclosures/21-5121r2).

\section{REFERENCES}

[1] Blazer DG, Domnitz S, Liverman CT, Committee on Accessible and Affordable Hearing Health Care for Adults (AHHC), National Academies of Sciences Engineering and Medicine (2016) Hearing health care services: Improving access and quality. In Hearing Health Care for Adults: Priorities for Improving Access and Affordability: National Academies Press, US, pp. 1-308.

[2] Cruickshanks KJ, Wiley TL, Tweed TS, Klein BEK, Klein R, Mares-Perlman JA, Nondahl DM (1988) Prevalence of hearing loss in older adults in Beaver Dam, Wisconsin: The Epidemiology of Hearing Loss Study. Am J Epidemiol 148, 879-86.

[3] World Health Organisation (WHO) (2021) Deafness and hearing loss https://www.who.int/health-topics/hearingloss\#tab=tab_1, Last updated 4 March 2021, Accessed on July 22, 2021.

[4] Taljaard DS, Olaithe M, Brennan-Jones CG, Eikelboom RH, Bucks RS (2016) The relationship between hearing impairment and cognitive function: A meta-analysis in adults. Clin Otolaryngol 41, 718-729.

[5] Loughrey DG, Kelly ME, Kelley GA, Brennan S, Lawlor BA (2018) Association of age-related hearing loss with cognitive function, cognitive impairment, and dementia: A systematic review and meta-analysis. JAMA Otolaryngol Head Neck Surg 144, 115-126.

[6] Livingston G, Sommerlad A, Orgeta V, Costafreda SG, Huntley J, Ames D, Ballard C, Banerjee S, Burns A, CohenMansfield J, Cooper C, Fox N, Gitlin LN, Howard R, Kales HC, Larson EB, Ritchie K, Rockwood K, Sampson EL, Samus Q, Schneider LS, Selbaek G, Teri L, Mukadam N (2017) Dementia prevention, intervention, and care. Lancet 390, 2673-2734.

[7] Osler M, Christensen GT, Mortensen EL, Christensen K, Garde E, Rozing MP (2019) Hearing loss, cognitive ability, and dementia in men age 19-78 years. Eur J Epidemiol 34, 125-130.

[8] Liu C-M, Lee C (2019) Association of hearing loss with dementia. JAMA Netw 2, e198112.

[9] Alzheimer's Association (2020) Alzheimer's disease facts and figures. Alzheimers Dement 16, 391-460.

[10] Burnham SC, Bourgeat P, Doré V, Savage G, Brown B, Laws S, Maruff P, Salvado O, Ames D, Martins RN, Masters CL, Rowe CC, Villemagen VL, AIBL Research Group (2016) Clinical and cognitive trajectories in cognitively healthy elderly individuals with suspected non-Alzheimer's disease pathophysiology (SNAP) or Alzheimer's disease pathology: A longitudinal study. Lancet Neurol 15, 1044-1053. 
[11] van der Kall LM, Truong T, Burnham SC, Doré V, Mulligan RS, Bozinovski S, Lamb F, Bourgeat P, Fripp J, Schuktz S, Lim YY, Laws S, Ames D, Fowler C, Rainey-Smith S, Martins RN, Salvado O, Robertson J, Maruff P, Masters CL, Villemagne VL, Rowe CC (2021) Association of $\beta$-amyloid level, clinical progression, and longitudinal cognitive change in normal older individuals. Neurology 96, e662-e670.

[12] Fowler C, Rainey-Smith SR, Bird S, Bomke J, Bourgeat P, Brown BM, Burnham SC, Bush A, Chadunow C, Collins S, James Doecke, Doré V, Ellis KA, Evered L, Fazlollahi A, Fripp J, Gardener SL, Gibson S, Grenfell R, Harrison E, Head R, Jin L, Kamer A, Lamb F, Lautenschlager NT, Laws SM, Li QX, Lim L, Lim YY, Louey A, MacAulay SL, MacKintosh L, Martins RN, Maruff P, Masters CL, McBride S, Milicic L, Peretti M, Pertile K, Porter T, Radler M, Rembach A, Robertson J, Rodrigues M, Rowe CC, Rumble R, Salvado O, Savage O, Silbert B, Soh M, Hamid RS, Taddei K, Taddei T, Thai C, Trounson B, Tyrrell R, Vacher M, Varghese S, Villemagne VL, Weinborn M, Woodward M, Xia Y, Ames D, AIBL (2021) Fifteen years of the Australian Imaging, Biomarkers and Lifestyle (AIBL) Study: Progress and observations from 2,359 older adults spanning the spectrum from cognitive normality to Alzheimer's disease. J Alzheimers Dis Rep $\mathbf{5}$, 443-468.

[13] Bourgeat P, Villemagne VL, Dore V, Brown B, Macaulay SL, Martins R, Masters CL, Ames D, Ellis K, Rowe CC (2015) Comparison of MR-less PiB SUVR quantification methods. Neurobiol Aging 36, S159-S166.

[14] Klunk WE, Koeppe RA, Price JC, Benzinger TL, Devous Sr MD, Jagust WJ, Johnson KA, Mathis CA, Minhas D, Pontecorvo MJ (2015) The Centiloid Project: Standardizing quantitative amyloid plaque estimation by PET. Alzheimers Dement 11 1-15. e4.

[15] Bourgeat P, Doré V, Fripp J, Ames D, Masters CL, Salvado O, Villemagne VL, Rowe CC, AIBL Research Group (2018) Implementing the centiloid transformation for $11 \mathrm{C}-\mathrm{PiB}$ and $\beta$-amyloid 18F-PET tracers using CapAIBL. Neuroimage 183, 387-393.

[16] Manjón JV, Coupé P, Raniga P, Xia Y, Desmond P, Fripp J, Salvado O (2018) MRI white matter lesion segmentation using an ensemble of neural networks and overcomplete patch-based voting. Comput Med Imaging Graph 69, 43-51.

[17] Falleti MG, Maruff P, Collie A, Darby DG (2006) Practice effects associated with the repeated assessment of cognitive function using the Cogstate Battery at 10-minute, one week and one month test-retest intervals. J Clin Exp Neuropsychol 28, 1095-1112.

[18] Maruff P, Thomas E, Cysique L, Brew B, Collie A, Snyder P, Piettrazak RH (2009) Validity of the CogState Brief Battery: Relationship to standardized tests and sensitivity to cognitive impairment in mild traumatic brain injury, schizophrenia, and AIDS dementia complex. Arch Clin Neuropsychol 24, 165-178.

[19] Westerman R, Darby DG, Maruff P, Collie A (2001) Computer-assisted cognitive function assessment of pilots. ADF Health 2, 29-36.

[20] Collie A, Maruff P, Makdissi M, McCrory P, McStephen M, Darby D (2003) CogSport: Reliability and correlation with conventional cognitive tests used in postconcussion medical evaluations. Clin J Sport Med 13, 28-32.

[21] Lim YY, Pietrzak RH, Ellis K, Jaeger J, Harrington K, Ashwood T, Szoeke C, Martins R, Bushka AI, Masters C, Rowe C, Villemagne VL, Ames D, Darby D, Maruff P (2013)
Rapid decline in episodic memory in healthy older adults with high amyloid- $\beta$. J Alzheimers Dis 33, 675-679.

[22] Maruff P, Lim YY, Darby D, Ellis KA, Pietrzak RH, Snyder PJ, Bush A, Szoeke C, Schembri A, Ames D, Masters CL, AIBL Research Group (2013) Clinical utility of the Cogstate Brief Battery in identifying cognitive impairment in mild cognitive impairment and Alzheimer's disease. BMC Psychol 1, 30.

[23] Lim YY, Ellis KA, Harrington K, Ames D, Martins RN, Masters CL, Rowe C, Savage G, Szoeke C, Darby D, Maruff P, AIBL Research Group (2012) Use of the Cogstate Brief Battery in the assessment of Alzheimer's disease related cognitive impairment in the Australian Imaging, Biomarkers and Lifestyle (AIBL) study. J Clin Exp Neuropsychol 34, 345-358.

[24] Huang B, Cao G, Duan Y, Yan S, Yan M, Yin P, Jiang H (2019) Gender differences in the association between hearing loss and cognitive function. Am J Alzheimers Dis Other Dement 35, 1533317519871167.

[25] Yantis PA (1985) Pure tone air-conduction testing. In Handbook of Clinical Audiology, Katz J, Gabbay WL, Ungerleider DS, Wilde L, eds. Williams \& Wilkins, Baltimore, MD, pp. 153-169.

[26] Roth TN, Hanebuth D, Probst R (2011) Prevalence of age-related hearing loss in Europe: A review. Eur Arch Otorhinolaryngol 268, 1101-1107.

[27] Mormino EC, Papp KV (2018) Amyloid accumulation and cognitive decline in clinically normal older individuals: Implications for aging and early Alzheimer's disease. $J$ Alzheimers Dis 64, S633-S646.

[28] Rowe C, Ellis K, Rimajova M, Bourgeat P, Pike KE, Jones G, Fripp J, Tochon-Danguy H, Morandeau L, O'Keefe GO, Price R, Raniga P, Robins P, Acosta O, Lenzo N, Szoeke C, Salvado O, Head R, Martins R, Masters CL, Ames D, Villemagne VL (2010) Amyloid imaging results from the Australian Imaging, Biomarkers and Lifestyle (AIBL) study of aging. Neurobiol Aging 31, 1275-1283.

[29] Golub JS, Sharma RK, Rippon BQ, Brickman AM, Luchsinger JA (2021) The association between early agerelated hearing loss and brain $\beta$-amyloid. Laryngoscope 131, 633-638.

[30] Parker T, Cash DM, Lane C, Lu K, Malone IB, Nicholas JM, James S, Keshava A, Murray-Smith H, Wong A (2020) Pure tone audiometry and cerebral pathology in healthy older adults. J Neurol Neurosurg Psychiatry 91, 172-176.

[31] Neff RM, Jicha G, Westgate PM, Hawk GS, Bush ML, McNulty B (2019) Neuropathological findings of dementia associated with subjective hearing loss. Otol Neurotol 40, e883-e893.

[32] Xu W, Zhang C, Li J-Q, Tan C-C, Cao X-P, Tan L, Yu JT, Alzheimer's Disease Neuroimaging Initiative (2019) Agerelated hearing loss accelerates cerebrospinal fluid tau levels and brain atrophy: A longitudinal study. Aging 11, 31563169.

[33] Mitchell BL, Thorp JG, Evans DM, Nyholt DR, Martin NG, Lupton MK (2020) Exploring the genetic relationship between hearing impairment and Alzheimer's disease. Alzheimers Dement (Amst) 12, e12108.

[34] Hardy J, Selkoe DJ (2002) The amyloid hypothesis of Alzheimer's disease: Progress and problems on the road to therapeutics. Science 297, 353-356.

[35] Bilgel M, Jedynak BM, Alzheimer's Disease Neuroimaging Initiative (2019) Predicting time to dementia using a quantitative template of disease progression. Alzheimers Dement (Amst) 11, 205-215. 
[36] Oh H, Madison C, Villeneuve S, Markley C, Jagust WJ (2013) Association of gray matter atrophy with age, $\beta$-amyloid, and cognition in aging. Cereb Cortex 24, 16091618.

[37] Hedden T, Oh H, Younger AP, Patel TA (2013) Metaanalysis of amyloid-cognition relations in cognitively normal older adults. Neurology 80, 1341-1348.

[38] Melzer TR, Stark MR, Keenan RJ, Myall DJ, MacAskill MR, Pitcher TL, Livingston L, Grenfell S, Horne KL, Young BN, Pascoe MJ, Almuqbel MM, Wang J, Marsh SH, Miller DH, Daltymple-Alford JC, Anderson TJ (2019) Beta amyloid deposition is not associated with cognitive impairment in Parkinson's disease. Front Neurol 10, 391.

[39] Lin F, Ferrucci L, An Y, Goh J, Doshi J, Metter E, Davatzikos C, Kraut MA, Resnick SM (2014) Association of hearing impairment with brain volume changes in older adults. $\mathrm{Neu}$ roimage 14, 84-92.

[40] Peelle JE, Troiani V, Grossman M, Wingfield A (2011) Hearing loss in older adults affects neural systems supporting speech comprehension. J Neurosci 31, 12638-12643.

[41] Armstrong NM, Williams OA, Landman BA, Deal JA, Lin FR, Resnick SM (2020) Association of poorer hearing with longitudinal change in cerebral white matter microstructure. JAMA Otolaryngol Head Neck Surg 146, 1035-1042.

[42] Golub JS (2017) Brain changes associated with age-related hearing loss. Curr Opin Otolaryngol Head Neck Surg 25, 347-352.

[43] Fulton SE, Lister JJ, Bush ALH, Edwards JD, Andel R (2015) Mechanisms of the hearing-cognition relationship. Semin Hear 36, 140-149.

[44] Griffiths TD, Lad M, Kumar S, Holmes E, McMurray B, Maguire EA, Billig AJ, Sedley W (2020) How can hearing loss cause dementia? Neuron 108, 401-412.

[45] Livingston G, Huntley J, Sommerlad A, Ames D, Ballard C, Banerjee S, Costafreda S, Dias A, Fox N, Gitlin LN, Howard R, Kales HC, Kivimaki M, Larson EB, Ogunniyi A, Orgeta V, Ritchie K, Rockwood K, Sampson EL, Samus Q, Schneider LS, Selbaek G, Teri L, Mukadam N (2020) Dementia prevention, intervention, and care: 2020 report of the Lancet Commission. Lancet 396, 413-446.
[46] Sinha UK, Hollen KM, Rodriguez R, Miller CA (1993) Auditory system degeneration in Alzheimer's disease. Neurology $\mathbf{4 3}, 779-785$.

[47] Busche M, Hyman BT (2020) Synergy between amyloid- $\beta$ and tau in Alzheimer's disease. Nat Neurosci 23, 1183-1193.

[48] Busche MA, Wegmann, S, Dujardin S, Commins C, Schiantarelli J, Klickstein N, Kamath TV, Carlson GA, Nelken I, Hyman BT (2019) Tau impairs neural circuits, dominating amyloid- $\beta$ effects, in Alzheimer models in vivo. Nat Neurosci 22, 57-64.

[49] Stevenson JS, Clifton L, Kuźma E, Littlejohns TJ (2021) Speech-in-noise hearing impairment is associated with an increased risk of incident dementia in 82,039 UK Biobank participants. Alzheimers Dement, doi: 10.1002/alz.12416.

[50] Lee S, Park K, Kim L-S, Kim H (2016) Effects of noise level and cognitive function on speech perception in normal elderly and elderly with amnestic mild cognitive impairment. Cogn Behav Neurol 29, 68-77.

[51] Johnson JCS, Marshall CR, Weil RS, Bamiou D-E, Hardy CJD, Warren JD (2021) Hearing and dementia: From ears to brain. Brain 144, 391-401.

[52] Wayne RV, Jonsrude IS (2015) A review of causal mechanisms underlying the link between age-related hearing loss and cognitive decline. Ageing Res Rev 23, 154-166.

[53] Gaetani L, Blennow K, Calabresi P, Di Filippo M, Parnetti L, Zetterberg H (2019) Neurofilament light chain as a biomarker in neurological disorders. J Neurol Neurosurg Psychiatry 90, 870-881. 